Article

\title{
Microbial Modifications of Androstane and Androstene Steroids by Penicillium vinaceum
}

\author{
Anna Panek*, Paulina Łyczko® and Alina Świzdor \\ Department of Chemistry, Wrocław University of Environmental and Life Sciences, 50-375 Wrocław, Poland; \\ paulina.lyczko@upwr.edu.pl (P.Ł.); alina.swizdor@upwr.edu.pl (A.Ś.) \\ * Correspondence: anna.panek@upwr.edu.pl \\ Academic Editors: Rafal R. Sicinski and Akihito Yokosuka \\ check for \\ updates
}

Received: 30 July 2020; Accepted: 13 September 2020; Published: 15 September 2020

\begin{abstract}
The biotransformation of steroid compounds is a promising, environmentally friendly route to new pharmaceuticals and hormones. One of the reaction types common in the metabolic fate of steroids is Baeyer-Villiger oxidation, which in the case of cyclic ketones, such as steroids, leads to lactones. Fungal enzymes catalyzing this reaction, Baeyer-Villiger monooxygenases (BVMOs), have been shown to possess broad substrate scope, selectivity, and catalytic performance competitive to chemical oxidation, being far more environmentally green. This study covers the biotransformation of a series of androstane steroids (epiandrosterone and androsterone) and androstene steroids (progesterone, pregnenolone, dehydroepiandrosterone, androstenedione, 19-OH-androstenedione, testosterone, and 19-nortestosterone) by the cultures of filamentous fungus Penicillium vinaceum AM110. The transformation was monitored by GC and the resulting products were identified on the basis of chromatographic and spectral data. The investigated fungus carries out effective Baeyer-Villiger oxidation of the substrates. Interestingly, introduction of the 19-OH group into androstenedione skeleton has significant inhibitory effect on the BVMO activity, as the 10-day transformation leaves half of the 19-OH-androstenedione unreacted. The metabolic fate of epiandrosterone and androsterone, the only $5 \alpha$-saturated substrates among the investigated compounds, is more complicated. The transformation of these two substrates combined with time course monitoring revealed that each substrate is converted into three products, corresponding to oxidation at C-3 and C-17, with different time profiles and yields.
\end{abstract}

Keywords: biotransformations; steroids; 19-hydroxyandrostenedione; 19-nortestololactone; lactonization; Baeyer-Villiger oxidation; Penicillium vinaceum

\section{Introduction}

The diversity of chemicals used by contemporary industry, medicine, and agriculture requires a constant search for new or more efficient synthetic routes and catalysts. Microbial enzymes and whole-cell catalytic systems seem to be an almost infinite reservoir of catalysts, with the benefit of relative ease of maintenance, mild reaction conditions, and low environmental track. Moreover, microbes exist in virtually all environments on Earth able to sustain life, from the polar regions [1] through dry deserts, to marine hydrothermal vents. Enzymes from such microorganisms must be able to operate in very diverse conditions of temperature (ranging from Arctic cold [2] to boiling water [3]), salinity, $\mathrm{pH}$, or pressure. Although the last two decades have brought some shift in our approach to the marine, extreme, or isolated environments, from the use of natural products towards the isolation and identification of enzymes or microorganisms with desired biotransformation properties, a recent review [4] points out that the potential of catalytic activity found in these environments is still underexplored. 
One of the fungal species with such underexplored potential is Penicillium vinaceum, first described in 1927 [5], and present in soil and marine environments. This species was shown to produce several known compounds of biochemical interest: cyclo (D-tryptophanyl-L-prolyl), citreoisocoumarin, brevianamide F, indol-3-carbaldehyde, $\alpha$-cyclopiazonic acid, terretrione A [6], and one product specific to this fungus, a diketopiperazine alkaloid penicillivinacine with antimigratory activity against the human breast cancer cells similar to terretrione A [7]. On the other hand, little is known of its biotransformation potential. P. vinaceum was shown to be ineffective in the reduction of methyl cinnamate to 2-phenoxyethanol [8], but its enzymatic system is able to carry out effective transglycosylation leading to functionalized alkyl $\alpha$-D-galactopyranosides, potentially useful biopolymers [9]. Several patent applications related to the biotransformations with P. vinaceum were filed: reduction of tetrahydrothiophen-3-one to $(R)$-tetrahydrothiophen-3-ol [10], conversion of eugenol to coniferyl aldehyde [11], and production of 3 $\beta$-hydroxy-17a-oxa-D-homo-androst-5-en-17-one [12]. The last reaction is an example of a process constituting the main research subject of the current study: enzymatic Baeyer-Villiger oxidation of steroidal substrates.

Baeyer-Villiger oxidation (BVO), first reported in 1899 [13], involves the action of peroxides or peroxyacids on ketones, with the insertion of an oxygen atom into the carbon chain at the carbonyl group. Esters are formed from acyclic ketones, while cyclic substrates are converted to lactones. Industrial applications of BVO are diverse, ranging from the production of monomers for polymerization to obtaining antibiotic medicines, steroids, and pheromones [14]. The original oxidizers, peroxyacids, are problematic in many aspects: they are unstable or even explosive, environmentally unfriendly (each reacting peroxyacid molecule turns into a carboxylate anion which must then be disposed of), the solvents frequently contain chlorinated hydrocarbons, and the reactions are far from being optimal with regard to the substrate specificity, chemo-, regio-, or enantioselectivity. Large progress was made with the use of hydrogen peroxide as a greener, environmentally friendly oxidizer for chemical BVO [15], but even the most recent accomplishments which fine-tune chemical BVO to obtain high selectivity and yields [16] use organic solvents as reaction media. On the other hand, the use of isolated enzymes or whole-cell biocatalysts seems to be a tempting alternative able to solve the environmental issues of chemical BVO. Several recent comprehensive reviews $[17,18]$ summarize the research into the microbial Baeyer-Villiger oxidation reactions since late 1940s, from pure research to the development of bioprocesses. The latter review concludes with such statements as "the real break-through of the BV biooxidation in industry has still not been realized. Hence, it is a prime time to seek out new targets for BV biooxidations" [18]. Interestingly, many compounds considered nowadays as biotransformation targets are steroids, the same class of substances found in the first reports on microbial Baeyer-Villiger oxidation $[19,20]$.

Importance of steroids for life is underlined by their diverse and ubiquitous roles in cellular biochemistry: participation of cholesterol in cell membranes, digestion facilitated by bile acids, and most importantly for medicinal applications, the hormonal activity of many steroid derivatives. The last factor is crucial for the use of steroid derivatives in medicine (as anti-inflammatory and anti-cancer medications) and sport (anabolic drugs). Recent reports have turned our attention especially towards 19-hydroxy steroidal derivatives: 19-OH-androstenedione has been shown to participate in neuroendocrine trans-differentiation of prostate cancer cells [21], while a new biocatalytic route was devised [22] leading to 19-OH-cortexolone, 19-OH-androstenedione, and ultimately to numerous C19-hydroxysteroids and 19-norsteroids with antitumor and insecticidal activities. Therefore we have included representatives of 19-OH steroids in our biotransformation experiments. Biosynthetic routes from 19-nortestosterone to 19-nortestololactone were established with the use of biocatalytic fungi Aspergillus tamarii [23] and Penicillium notatum [24], but we were able to obtain in the current study better final yields than those presented in the earlier reports.

Baeyer-Villiger oxidation of steroids to steroidal lactones is one of the routes pursued in the search for new bioactive compounds. The enzymes responsible for this process are Baeyer-Villiger monooxygenases (BVMOs). While their sequences and phylogenetic tree have been intensively 
explored [18], much less is known about the structural aspects of BVMOs. Only recently were some bacterial and fungal BVMOs with steroids in their substrate scope crystallized and their 3D structures determined by crystallographic methods: a steroid monooxygenase from Rhodococcus rhodochrous [25], and a versatile polycyclic ketone monooxygenase (PockeMO) from the thermophilic fungus Thermothelomyces thermophile [26].

Microbial BVMOs have considerably broad substrate scope, for example the PockeMO can oxidize both A and D rings of the steroidal substrates [26], and this versatility is related to the structure of substrate binding pocket, able to accept bulky substrates in diverse configurations [26,27]. Such an idea of configurational flexibility of steroid substrates was proposed already in 1967 on the basis of diverse metabolic fates of steroids biotransformed by Aspergillus tamarii cultures [28]. Some recent examples of the presence of steroidal BVMOs in fungal biotransformation pathways are: lactonization of progesterone and 5-ene steroids [29,30]; lactonization of dehydroepiandrosterone (DHEA), pregnenolone, and androstenedione by filamentous fungi of genus Penicillium [31,32]; lactonization of DHEA by Aspergillus parasiticus [33]; ring-D lactonization of steroidal C-17 ketones to $11 \alpha$-hydroxy derivatives by Beauveria bassiana [34]; activity of Penicillium lanosocoeruleum in ring-D lactonization of $\mathrm{C}_{19}$-steroids [35] and pregnene-based steroids [36]; biotransformation of DHEA into hydroxylated steroid lactones Spicaria fumoso-rosea [37]; diverse biotransformation routes of steroids, including ring-D lactonization, in the cultures of Penicillium notatum [24] and Aspergillus terreus [38]; formation of testololactone from diverse steroidal substrates with the use of a multifunctional strain of Penicillium simplicissimum [39]; cascade of DHEA biotransformations by Beauveria species [40]; and the formation of new derivatives of $3 \beta$-acetyloxy- $5 \alpha$-chloro-6,19-oxidoandrostan-17-one [41]. This rich background of BVMO activity studies in fungal species, combined with the outlined above need for further research in the field of biotransformations, prompted us to investigate in detail metabolic fates of DHEA (1), epiandrosterone (2), androsterone (3), androstenedione (4), 19-OH-androstenedione (5), testosterone (6), 19-nortestosterone (7), progesterone (8), and pregnenolone (9) in the cultures of Penicillium vinaceum AM110. The transformation progress was monitored by GC and TLC analysis and the resulting products were identified on the basis of chromatographic and spectral data.

\section{Results and Discussion}

Biotransformations of the chosen substrates by Penicillium vinaceum AM110 proceed according to one of two distinct schemes. Substrates $\mathbf{1}$ and 4-9 undergo Baeyer-Villiger lactonization in ring $\mathrm{D}$, and no other detectable products are formed. On the other hand, transformation of compounds 2 and 3, the only $5 \alpha$-saturated steroids in the investigated series of substrates, leads to a mixture of products. For this reason we have carried out transformations of $\mathbf{2}$ and $\mathbf{3}$ with time course monitoring of the composition of the reaction mixture. These two schemes of biotransformation will be described in separate subsections below. Scheme 1 presents the structures of the investigated compounds: substrates 1-9 and the corresponding products. 


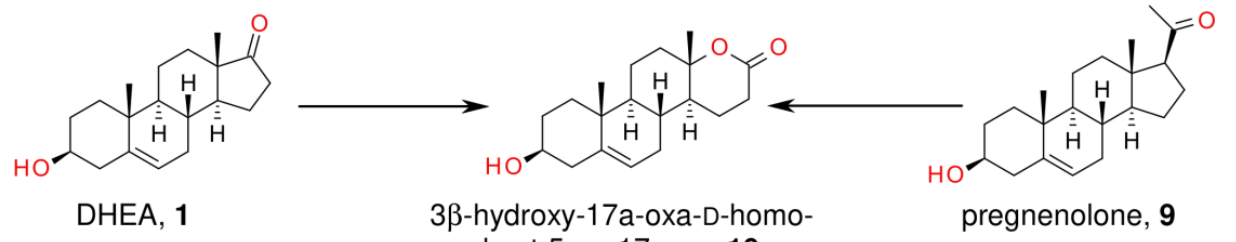
-androst-5-en-17-one, 10

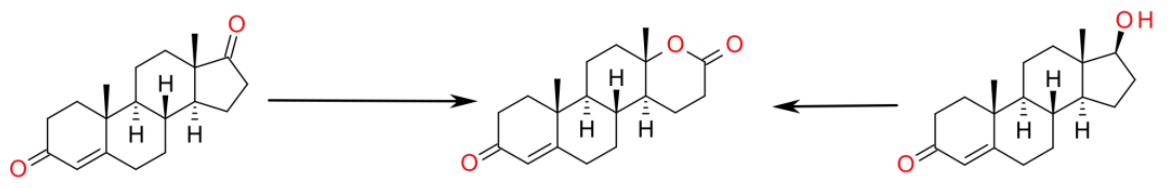

androstenedione, 4

testololactone, $\mathbf{1 1}$

testosterone, 6

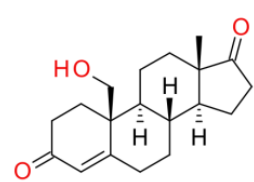

19-hydroxyandrostenedione, 5

19-nortestosterone, 7
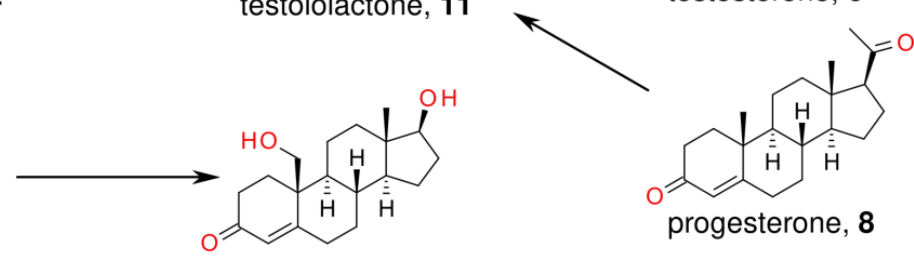

$17 \beta, 19$-dihydroxy-

androst-4-en-3-one, 12

(19-hydroxytestosterone)
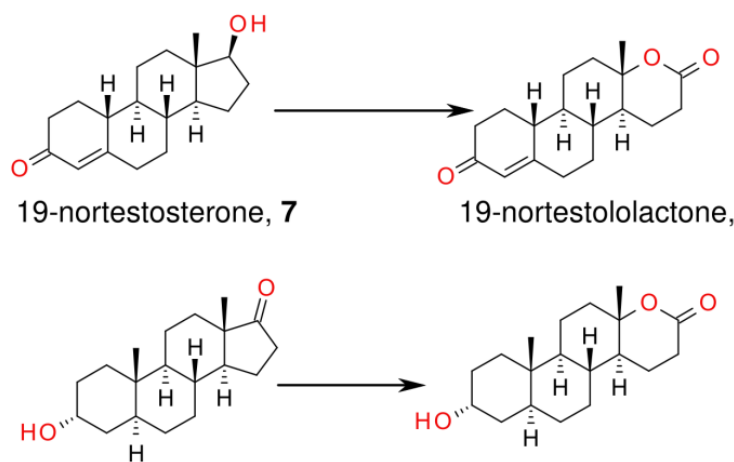

androsterone, 3<smiles>CC12CCC3C(CCC4CC(O)CCC43C)C1CCC2=O</smiles>

epiandrosterone, 2
$3 \alpha$-hydroxy-17a-oxa-D-homo$5 \alpha$-androstan-17-one, 17

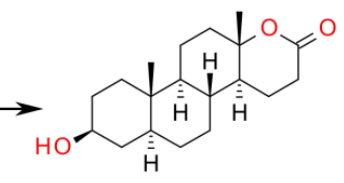

$3 \beta$-hydroxy-17a-oxa-D-homo$5 \alpha$-androstan-17-one, 16

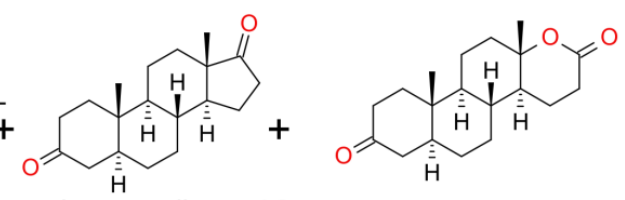

androstanedione, 14 17a-oxa-D-homo-5 $\alpha$ androstan-3,17-dione, 15

Scheme 1. Biotransformation of steroidal substrates 1-9 by P. vinaceum AM110-overview of the substrate and product structures.

\subsection{Baeyer-Villiger Oxidation of Steroidal Compounds by P. vinaceum AM110}

Our earlier studies with biotransformations of steroids by the fungi of genus Penicillium $[31,32,35,36]$ have revealed large diversity of metabolic fates of the substrates. Baeyer-Villiger oxidation, isomerizations, and hydroxylations with diverse product stereochemistry were found. On the other hand, the biocatalyst used in the current study, Penicillium vinaceum AM110, prefers to carry out only the BVO process for most of the substrates: 1, 4, and 6-9 (see Scheme 1 for a structural overview, and Table 1 for the detailed results of the transformations; in some cases the products were compounds for which we had no standard samples to compare with using the GC and TLC experiments, and these compounds were identified on the basis of NMR spectroscopy-see Section 2.3). In most cases the conversion ratio exceeds $90 \%$ in two days. An interesting exception is provided by 
19-hydroxyandrostenedione (5) where, after 10 days of transformation, only half of the substrate was transformed. The parent compound of 5, androstenedione (4), is converted in 95\% into testololactone in $48 \mathrm{~h}$. The ring-D Baeyer-Villiger lactonization of 4 was also the only process for this substrate in the cultures of P. lilacinum [31] and P. camemberti [32]. Its 19-OH derivative 5 is not affected by the BVMO, but it undergoes reduction at the same position C-17. Thus, introduction of the 19-OH function seems to obstruct the action of the fungal BVMO but not the action of a steroid 17 $\beta$-HSD (17 $\beta$-hydroxysteroid dehydrogenase).

Table 1. The final outcome of the transformation of steroidal compounds by Penicillium vinaceum.

\begin{tabular}{|c|c|c|c|c|}
\hline Substrate & $\begin{array}{c}\mathbf{R}_{t} \\
(\mathrm{~min})\end{array}$ & $\begin{array}{l}\text { Time } \\
(\mathrm{h} / \mathrm{d})\end{array}$ & $\begin{array}{l}\text { Steroidal Compounds Identified in the } \\
\text { Mixture }(\%)^{a}\end{array}$ & $\begin{array}{l}\text { Yield } \\
(\%)^{a, c}\end{array}$ \\
\hline \multirow{2}{*}{ DHEA (1) } & 4.20 & \multirow[t]{2}{*}{$24 \mathrm{~h}$} & \multirow{2}{*}{$\begin{array}{c}\text { DHEA } \\
\text { 3ß-Hydroxy-17a-oxa-D-homo-androst-5- } \\
\text { en-17-one }{ }^{b}(\mathbf{1 0})\end{array}$} & - \\
\hline & 7.79 & & & 96 \\
\hline \multirow{2}{*}{ Androstenedione (4) } & 5.29 & \multirow[t]{2}{*}{$48 \mathrm{~h}$} & Androstenedione & 5 \\
\hline & 9.32 & & Testololactone $^{\mathrm{b}}$ (11) & 95 \\
\hline \multirow{2}{*}{ 19-Hydroxyandrostenedione (5) } & 9.26 & \multirow[t]{2}{*}{$10 \mathrm{~d}$} & 19-Hydroxyandrostenedione & 54 \\
\hline & 9.43 & & 17 $\beta, 19$-dihydroxyandrost-4-en-3-one (12) & $46(40)$ \\
\hline \multirow{2}{*}{ Testosterone (6) } & 5.61 & \multirow[t]{2}{*}{$48 \mathrm{~h}$} & Testosterone & - \\
\hline & 9.32 & & Testololactone $^{\mathrm{b}}(\mathbf{1 1})$ & 100 \\
\hline \multirow{2}{*}{ 19-Nortestosterone (7) } & 5.19 & \multirow[t]{2}{*}{$6 \mathrm{~d}$} & 19-nortestosterone & 2 \\
\hline & 9.09 & & 19-nortestololactone (13) & $90(85)$ \\
\hline \multirow{2}{*}{ Progesterone (8) } & 7.51 & \multirow[t]{2}{*}{$72 \mathrm{~h}$} & Progesterone & 13 \\
\hline & 9.32 & & Testololactone $^{\mathrm{b}}(\mathbf{1 1})$ & 87 \\
\hline \multirow{2}{*}{ Pregnenolone (9) } & 6.22 & \multirow[t]{2}{*}{$48 \mathrm{~h}$} & Pregnenolone & 9 \\
\hline & 7.79 & & $\begin{array}{l}\text { 3ß-Hydroxy-17a-oxa-D-homo-androst-5- } \\
\text { en-17-one }{ }^{b}(\mathbf{1 0})\end{array}$ & 91 \\
\hline
\end{tabular}

${ }^{a}$ Determined by GC analysis of the crude chloroform (chloride methylene for (5)) extracts. ${ }^{b}$ Identified in GC and

TLC on the basis of comparison with standard samples. ${ }^{c}$ Isolated yield in parentheses.

An interesting perspective on the inhibition of the BVMO by the presence of the 19-OH function is provided by another pair of substrates, testosterone (6) and 19-nortestosterone (7). In this case, the 19-methyl group present in 6 is replaced by a hydrogen atom in 7 . This has only a moderate effect on the transformation kinetics: $\mathbf{6}$ is totally converted into testololactone in two days, while 7 is still present in minute amount ( $2 \%$ ) after six days of transformation. However, both $\mathbf{6}$ and $\mathbf{7}$ are converted into the corresponding lactones, and no traces of any reduced derivatives were observed. In the presented studies, in the course of a six-day biotransformation 19-nortestololactone (13) was obtained with good yield of $90 \%$. An established biosynthetic route to 19-nortestololactone utilizes $72 \mathrm{~h}$ transformation of 19-nortestosterone by Aspergillus tamarii with $70 \%$ yield $(16 \times 50 \mathrm{mg} / 500 \mathrm{~mL})$ [23]. In another known example of transformation of 19-nortestosterone by Penicillium notatum, 19-nortestololactone was obtained with 93\% yield, but at lower substrate concentration (100 mg/300 mL medium) [24] than in the current report. As a result of the 10-day transformation of 19-hydroxyandrostenedione (5), $17 \beta, 19$-dihydroxyandrost-4-en-3-one (12) (19-hydroxytestosterone) was obtained with $46 \%$ yield. In the case of 5, the BVMO activity and formation of the ring-D lactone derivative were not observed. To the best of our knowledge, we present the first described case of microbiological formation of 19-hydroxytestosterone from $17 \beta, 19$-dihydroxyandrost-4-en-3-one in the culture of P. vinaceum (obtained chemically by Ehrenstein and Otto [42]).

These results confirm the preference of many steroid substrates to undergo lactonization, observed in many studies [29-32,37]. This preference for lactonization includes also the fact that many of the substrates studied here are not lactones, but 17-hydroxy, 17-acetyl etc. derivatives. However, the compounds differing only by the C-17 function are converted to the same product: $\mathbf{1}$ as well as 9 yield 3 $\beta$-hydroxy-17a-oxa-D-homo-androst-5-en-17-one, while 4, 6, and 8 yield testololactone. Thus, 
successful BVMO activity requires also effective preceding steps leading to the cleavage or oxidation of the substituent at C-17, which was noted already by Sebek et al. [43].

The performance of BVMOs of the Penicillium vinaceum AM110 strain is comparable to other species of the genus Penicillium. For example, P. lanosocoeruleum converts progesterone to testololactone in $88 \%$ yield in $72 \mathrm{~h}$ (the value very similar to the current study), but pregnenolone is converted into a mixture of products, with only $44 \%$ yield of testololactone in $72 \mathrm{~h}$ [36] (in the current study on P. vinaceum, testololactone is the sole detected product with $91 \%$ yield after $48 \mathrm{~h}$ ). P. lanosocoeruleum converts DHEA (1) solely to testololactone with $96 \%$ yield in $24 \mathrm{~h} \mathrm{[35],} \mathrm{which} \mathrm{is} \mathrm{a} \mathrm{different} \mathrm{route,} \mathrm{including} \mathrm{isomerization,}$ than in the current study, where only BVO is observed. Interestingly, other Penicillium species also differ in their ability of DHEA conversion: P. lilacinum AM111 transforms DHEA completely in $30 \mathrm{~h}$ into the same product as in the current study, 3ß-hydroxy-17a-oxa-D-homo-androst-5-en-17-one [31], while P. camemberti AM83 exhibits two distinct metabolic routes for DHEA, both however converging into testololactone (85\% yield after $24 \mathrm{~h}$ ) [32].

Summarizing the ability of $P$. vinaceum to transform androstene substrates, we note that the metabolic fate of these substrates, leading to the corresponding lactones, is rather less complicated than in the other species of Penicillium genus, and the transformation kinetics and achieved yields are very promising.

\subsection{Transformations of $5 \alpha$-Saturated Steroids in the Cultures of P. vinaceum AM110}

The metabolic fate of androsterone (3) and epiandrosterone (2), representative biologically active $5 \alpha$-saturated steroids, turns out to be more complicated than the transformation of the unsaturated steroids described above. Initial tests indicated that $P$. vinaceum is able to transform 2 and 3 into a mixture of products oxidized at C-17 (BVMO activity, products 16 and 17), at C-3 (product 14, oxidation of the hydroxyl group to the corresponding ketone) or at both C-3 and C-17 (product 15). See Scheme 1 for the structures of the substrates and products. This fact, already observed, e.g., for P. lanosocoeruleum [35], prompted us to carry out transformations aimed at the time course analysis of the transformation progress. The results are summarized in Table 2, Figures 1 and 2.

Table 2. The time course of the transformation of epiandrosterone and androsterone by Penicillium vinaceum.

\begin{tabular}{|c|c|c|c|c|c|c|c|}
\hline \multirow{2}{*}{ Substrate } & \multirow{2}{*}{$\begin{array}{c}R_{t} \\
(\min )\end{array}$} & \multirow{2}{*}{$\begin{array}{c}\text { Compounds Identified in the } \\
\text { Mixture (\%) }\end{array}$} & \multicolumn{5}{|c|}{ Time of Transformation (h) } \\
\hline & & & 24 & 48 & 72 & 96 & $8 \mathrm{~d}$ \\
\hline \multirow{4}{*}{ Epiandrosterone (2) } & 4.51 & Epiandrosterone & 94 & 91 & 87 & 82 & 77.5 \\
\hline & 4.98 & Androstanedione ${ }^{\mathrm{b}}(\mathbf{1 4})$ & 2 & 2 & 3.5 & 4 & 5.5 \\
\hline & 8.95 & $\begin{array}{l}\text { 17a-Oxa-D-homo-5 } \alpha \text {-androstan-3, } \\
\text { 17-dione }{ }^{\mathrm{b}}(\mathbf{1 5})\end{array}$ & 2 & 3 & 4 & 4 & 5 \\
\hline & 8.43 & 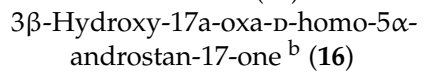 & 2 & 4 & 5.5 & 10 & 12 \\
\hline \multirow{4}{*}{ Androsterone (3) } & 4.68 & Androsterone & 92 & 83 & 38 & 18 & 15 \\
\hline & 4.98 & Androstanedione $^{\mathrm{b}}(\mathbf{1 4})$ & 4 & 8 & 10 & - & - \\
\hline & 8.95 & $\begin{array}{c}\text { 17a-Oxa-D-homo-5 } \alpha \text {-androstan-3, } \\
\text { 17-dione }{ }^{\mathrm{b}}(\mathbf{1 5})\end{array}$ & 2 & 3 & 12 & 22 & 32 \\
\hline & 8.48 & 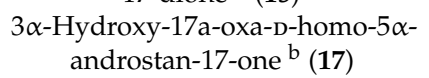 & 2 & 6 & 40 & 60 & 53 \\
\hline
\end{tabular}

${ }^{a}$ Determined by GC analysis of the crude chloroform extracts. ${ }^{b}$ Identified in GC and TLC on the basis of comparison with standard samples. 


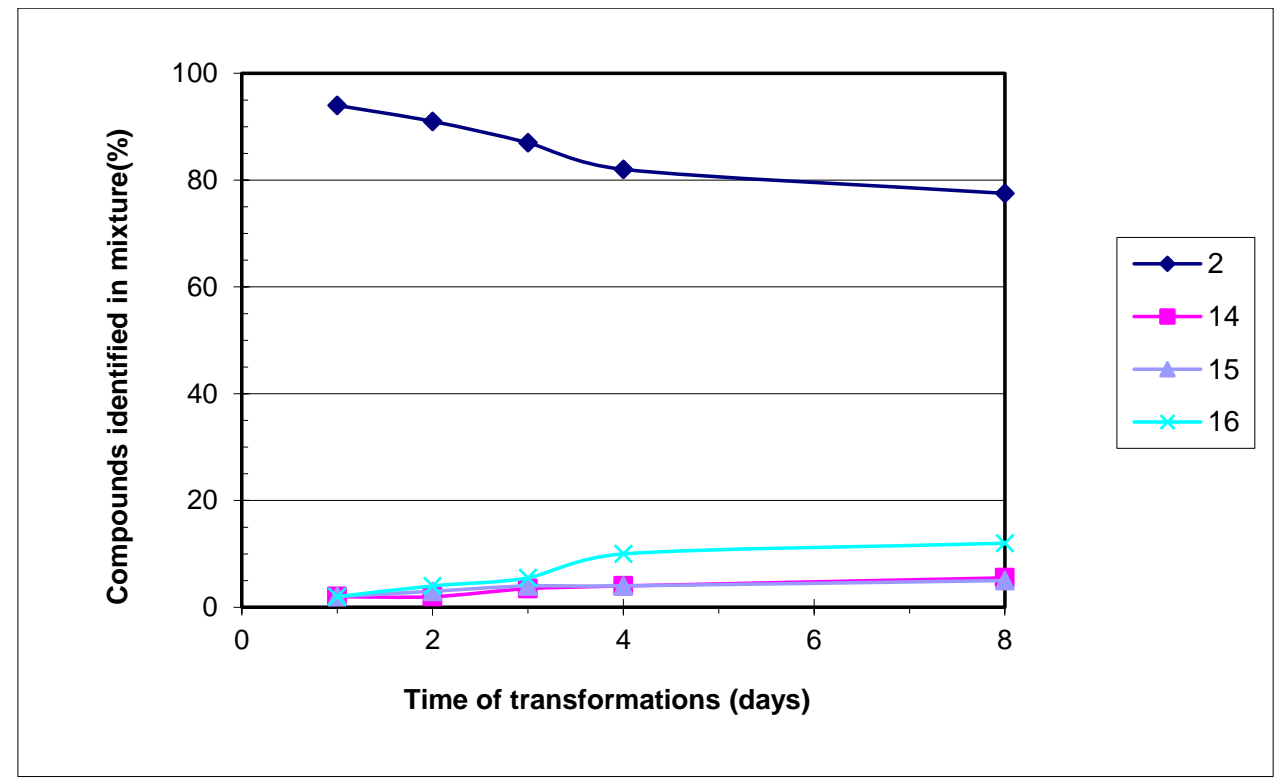

Figure 1. The time course of the transformation of epiandrosterone (2) by Penicillium vinaceum.

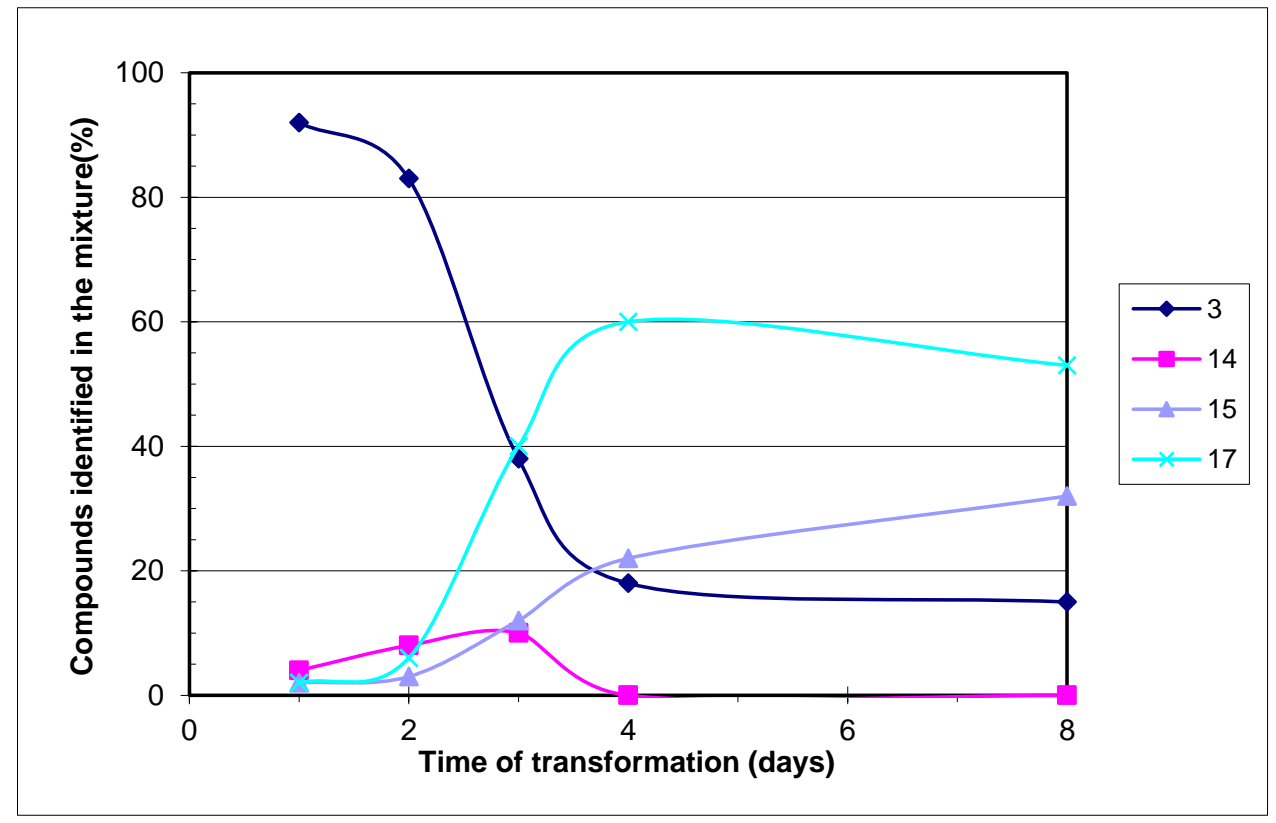

Figure 2. The time course of the transformation of androsterone (3) by Penicillium vinaceum.

An interesting feature of the $P$. vinaceum enzymatic system is strong discrimination of the oxidation kinetics on the basis of the C-3 stereochemistry. While 2 , a $3 \beta$-hydroxy steroid, is not readily transformed (even after eight days of transformation, still $77.5 \%$ of the unreacted $\mathbf{2}$ is present in the reaction mixture), its $3 \alpha$-hydroxy stereoisomer 3 is converted in $85 \%$, and the transformation is especially fast on the third day of the experiment. The oxidation kinetics is, however, generally noticeably slower than for the 5-ene steroids described in Section 2.1.

While transformation of epiandrosterone (2) progresses slowly and concentrations of products grow monotonically, the case of androsterone (3) is more interesting. Androstanedione, the carbonyl derivative of 3, formed by oxidation of the hydroxyl group at C-3, undergoes between 72 and $96 \mathrm{~h}$ further conversion, most probably BVO to the lactone 15. This assumption is supported by the fate of $3 \alpha$-hydroxy-17a-oxa-D-homo-5 $\alpha$-androstan-17-one (17), the product of the BVO retaining the $3 \alpha$-hydroxy function. This compound is the predominant one within the experimental time scale, 
but its amount decreases in the final period of transformation, while new, corresponding amount of $\mathbf{1 5}$ is formed. This progression of product concentrations shows that the enzyme oxidizing the hydroxyl group at C-3 to the ketone acts slower than the BVMO. Changing the configuration from $3 \beta$-hydroxy in epiandrosterone (2) to $3 \alpha$-hydroxy in androsterone (3) slowed down the transformation process and activity of Baeyer-Villiger monooxygenase.

It is also interesting to compare the transformation of DHEA (1) and its $5 \alpha$-saturated analog-epiandrosterone (2). The rapid conversion of 1 to $3 \beta$-hydroxy lactone (10) with high yield indicates that the substrate is the inducer of BVMO. In the case of transformation of 2 , we observed a significant reduction in the transformation rate and the catalytic activity of BVMO, indicating that epiandrosterone (2) may be the BVMO inhibitor.

\subsection{Spectroscopic Identification of Products $\mathbf{1 2}$ and $\mathbf{1 3}$}

The structures of the obtained and isolated products $\mathbf{1 2}$ and $\mathbf{1 3}$ were established by using spectroscopic techniques (IR, ${ }^{1} \mathrm{H}-\mathrm{NMR}$ and $\left.{ }^{13} \mathrm{C}-\mathrm{NMR}\right)$. The assumed structures were confirmed by comparison of the characteristic shift values of selected, diagnostic signals of the products and starting compounds.

The ${ }^{1} \mathrm{H}$ NMR spectrum of 12 features a characteristic signal at $\delta_{\mathrm{H}} 3.63 \mathrm{ppm}(\mathrm{t}, J=8.5 \mathrm{~Hz}, 17 \alpha-\mathrm{H})$ from the proton at C-17. Further, in the ${ }^{13} \mathrm{C}$ NMR spectrum of 12 a new signal appears at $\delta_{\mathrm{C}} 81.5 \mathrm{ppm}$ and no signal at $\delta_{C} 220.3$ ppm is observed (present in the substrate), which unanimously indicates reduction of the ring-D carbonyl group to the hydroxyl group at $17 \beta$ position, accompanied by an upfield shift of the C-18 methyl group signal $(\Delta 0.122 \mathrm{ppm})$ and downfield shift of the $4-\mathrm{H}$ signal $(\Delta 0.013 \mathrm{ppm})$ in the ${ }^{1} \mathrm{H}$ NMR spectrum. The signals at $\delta_{\mathrm{H}} 3.90 \mathrm{ppm}(\mathrm{d}, J=11 \mathrm{~Hz})$ and at $\delta_{\mathrm{H}} 4.06 \mathrm{ppm}$ $\left(\mathrm{dd}, J_{1}=1 \mathrm{~Hz}, J_{2}=11 \mathrm{~Hz}\right)$ are formed by two protons of the methylene group at $\mathrm{C}-19$, and indicate the close proximity of a hydroxyl group proton $\left(19-\mathrm{CH}_{2}-\mathrm{OH}\right)$. The signal appearing as a broad singlet at $\delta_{\mathrm{H}} 5.94$ ppm points to the presence of a double bond at the C-4 carbon atom.

The analysis of the ${ }^{1} \mathrm{H}$ NMR and ${ }^{13} \mathrm{C}$ NMR spectral data indicates that the formed product 12 is $17 \beta, 19$-dihydroxyandrost-4-en-3-one.

In the ${ }^{1} \mathrm{H}$ NMR spectrum of 13 a significant downfield shift was observed for the 18-methyl resonance signals in comparison with the substrate (from $\delta_{\mathrm{H}} 0.81$ to $\delta_{\mathrm{H}} 1.36 \mathrm{ppm}$ ). It was consistent with an oxygen atom insertion into the ring $\mathrm{D}$. This was supported by the ${ }^{13} \mathrm{C}$ NMR spectrum in which the C-13 resonance signal had undergone a downfield shift of ca. $52 \mathrm{ppm}$ (from $\delta_{\mathrm{C}} 30.7$ to $\delta_{\mathrm{C}}$ $82.9 \mathrm{ppm}$ ). The lactonization via Baeyer-Villiger oxidation in the ring $\mathrm{D}$ of 19-nortestololactone was confirmed by the appearance of the signal at $\delta_{C}$ ca. $171 \mathrm{ppm}(\mathrm{C}-17)$. The H-17 $\alpha$ triplet characteristic for 19-nortestosterone $\left(\delta_{\mathrm{H}} 3.66 \mathrm{ppm}, J=8.5 \mathrm{~Hz}\right)$ has disappeared, while the remaining signal of olefinic proton $\delta_{\mathrm{H}}$ ca. $5.84 \mathrm{ppm}$ in the ${ }^{1} \mathrm{H}$ NMR spectrum and a non-protonated signal at $\delta_{\mathrm{C}} 199.5 \mathrm{ppm}$ in the ${ }^{13} \mathrm{C}$ NMR spectrum indicate the presence of 3-oxo-4-en moiety in the obtained product. The band at $1725 \mathrm{~cm}^{-1}$ in the IR spectrum confirmed the formation of the $\delta$-lactone structure. These facts are consistent with identification of $\mathbf{1 3}$ as 19-nortestololactone.

\section{Materials and Methods}

\subsection{Chemicals and Microorganism}

The substrates, namely DHEA (dehydroepiandrosterone, $3 \beta$-hydroxyandrost-5-en-17-one, 1), epiandrosterone ( $3 \beta$-hydroxy- $5 \alpha$-androstan-17-one, 2$)$, androsterone ( $3 \alpha$-hydroxy- $5 \alpha$-androstan- 17 -one, 3), androstenedione (androst-4-ene-3-one, 4), 19-hydroxyandrostenedione (19-hydroxyandrost4-ene-3,17-dione, 5), testosterone (6), 19-nortestosterone (7), progesterone (8), and pregnenolone (9) standards, were purchased from Sigma-Aldrich Chemical Co. (St. Louis, MO, USA)

The fungal strain Penicillium vinaceum AM110 used for biotransformations was taken from the collection of Department of Chemistry, Wrocław University of Environmental and Life Sciences, 
Wrocław, Poland. The strain was maintained on Sabouraud $4 \%$ dextrose-agar slopes and freshly subcultured before use in the transformation experiments.

\subsection{General Conditions of Cultivation and Biotransformation}

General experimental and fermentation details were described previously [31]. After 4 days of growth period of $P$. vinaceum AM110, a given substrate was added to each flask in an amount necessary to obtain $0.30 \mathrm{~g} \mathrm{~L}^{-1}$ final substrate concentration $\left(0.50 \mathrm{~g} \mathrm{~L}^{-1}\right.$ final substrate concentration for 19-nortestosterone). The transformation was carried out at $25^{\circ} \mathrm{C}$ in a rotary shaker $(180 \mathrm{rpm})$ for eight days (for 19-hydroxyandrostenedione the time was prolonged to 10 days, while for 19-nortestosterone, the transformation lasted six days) with periodic checks of the presence of the substrate in the reaction mixture and the stability of the obtained products (see below for the details of the checks). Each experiment was performed with three replications (five replications for transformation of 19-hydroxyandrostenedione).

The monitoring of the time-dependent progress of the bioconversion and determination of the metabolic pathways of substrates was carried out as follows. The 5-mL samples of the broth were taken out at regular intervals $(24,48,72$, and $96 \mathrm{~h}$ from the start) from the reaction flask, extracted with organic solvents (chloroform or methylene chloride), and analyzed by comparison of the GC and TLC data with those of authentic samples. The final samples, taken at the end of transformation $(6,8$, or 10 days, depending on the substrate, as described above), served as the control of the extended metabolic fate of the substrates and products.

\subsection{Isolation and Identification of the Products}

Briefly, $3 \alpha$-Hydroxy-17a-oxa-D-homo-5 $\alpha$-androstan-17-one (17), 3 $\beta$-hydroxy-17a-oxa-D-homo- $\alpha \alpha$ -androstan-17-one (16) and 17a-oxa-D-homo-5 $\alpha$-androstan-3,17-dione (15) were obtained previously in our laboratory by transformation by Penicillium lanosocoeruleum $\mathrm{KCH} 3012$ as described in our article [35]. 3 3-Hydroxy-17a-oxa-D-homo-androst-5-en-17-one (10) and testololactone (11) were obtained previously in our laboratory by transformation of DHEA by Penicillium lilacinum AM111 [31]. Androstanedione ( $5 \alpha$-androstan-3,17-dione) (14) was obtained by the oxidation of androsterone (3) with Jones' reagent [35]. The aforementioned compounds were used as analytical standards for the time course experiments.

Identification of the transformation products of substrates 1-9 was carried out on the basis of the GC and TLC (for 1: hexane/acetone (2:1 v:v); for 2: hexane/acetone (1:1 v:v); for 3: hexane/acetone (2:1 v:v); for 4: hexane/acetone (2:1 v:v), for 6: methyl chloride/acetone (4:1 v:v), for 8 ethyl acetate/methyl chloride/acetone (3:1:1 v:v:v), for 9: ethyl acetate/methyl chloride/acetone (3:1:1 v:v:v)) analysis by comparison of the retention times $(R t)$ with the $R t$ values of the standards available in our laboratory, which have been already identified in our earlier studies [31,35].

Isolation and identification (by ${ }^{1} \mathrm{H}$ NMR and ${ }^{13} \mathrm{C} N M R$ ) of the products were carried out for 19-hydroxyandrostenedione (5) and 19-nortestosterone (7), the two substrates purchased from Sigma-Aldrich Poland company, Poznań, Poland.

The products of biotransformation were extracted three times with chloroform (for substrates 1-4, 6-9) or chloride methylene (for substrate 5). The organic extracts were dried over anhydrous magnesium sulfate, concentrated in vacuo, and analyzed by TLC and GC. Products were separated by column chromatography on silica gel (Silica gel 60, 63-200 $\mu \mathrm{m}, 70-230$ mesh, Sigma-Aldrich, Buchs, Switzerland) with hexane/acetone (2:3 v:v) for 19-hydroxyandrostenedione, and hexane/acetone (1:1 v:v) for 19-nortestosterone, as eluents. TLC was carried out with Kieselgel $60 \mathrm{~F}_{254}$ plates (Merck, Darmstadt, Germany) using the same eluents. In order to develop the image, the plates were sprayed with solution of methanol in concentrated sulfuric acid (1:1) and heated to $120^{\circ} \mathrm{C}$ for $3 \mathrm{~min}$. GC analysis was performed using Hewlett Packard 5890A Series II GC instrument (FID, carrier gas $\mathrm{H}_{2}$ at flow rate of

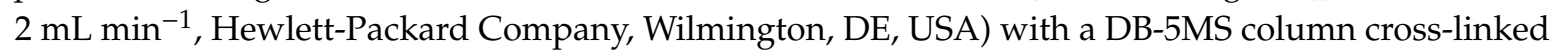
phenyl-methylsiloxane, $30 \mathrm{~m} \times 0.32 \mathrm{~mm} \times 0.25 \mu \mathrm{m}$ film thickness. The following program was used in 
the GC analysis: $220^{\circ} \mathrm{C} / 1 \mathrm{~min}$, gradient $4{ }^{\circ} \mathrm{C} / \mathrm{min}$ to $270{ }^{\circ} \mathrm{C}$ and $30{ }^{\circ} \mathrm{C} / \mathrm{min}$ to $300{ }^{\circ} \mathrm{C} / 3 \mathrm{~min}$ (for $1-6,8$, 9 substrates); $220^{\circ} \mathrm{C} / 1 \mathrm{~min}$, gradient $4{ }^{\circ} \mathrm{C} / \mathrm{min}$ to $260^{\circ} \mathrm{C}$ and $30^{\circ} \mathrm{C} / \mathrm{min}$ to $300^{\circ} \mathrm{C} / 3 \mathrm{~min}$ (for 7); injector and detector temperatures were $300^{\circ} \mathrm{C}$. The NMR spectra (for obtained products of transformation of 19-hydroxyandrostenedione and 19-nortestosterone) were measured in $\mathrm{CDCl}_{3}$ and recorded on a DRX 600 MHz Bruker Avance spectrometer (Bruker Polska, Poznań, Poland). Characteristic ${ }^{1} \mathrm{H}-$ and ${ }^{13} \mathrm{C}-\mathrm{NMR}$ shift values in comparison to the starting compounds were used to determine structures of metabolites, and in combination with DEPT analysis to identify the nature of the carbon atoms. Elemental analysis was performed on vario EL III analyzer (Elementar Analysensysteme GmbH, Hanau, Germany). Infrared spectra (IR) were recorded in KBr disc on a Mattson IR 300 Spectrometer (Mattson-Garvin Company, Maitland, FL, USA). Melting points were determined on a Boetius melting point apparatus and are uncorrected.

\subsection{Spectral Data of the Isolated Transformation Products}

17ק,19-dihydroxyandrost-4-en-3-one (12) $(60 \mathrm{mg}, 40 \% \mathrm{~mol}): \mathrm{C}_{19} \mathrm{H}_{28} \mathrm{O}_{3}$, Found: $\mathrm{C}, 74.89 ; \mathrm{H}, 9.26$. Requires C, 74.96; H, 9.27. m.p. 200-202 ${ }^{\circ} \mathrm{C}$ (lit. 200-204 ${ }^{\circ} \mathrm{C}$ [42]). IR: $v_{\max }\left(\mathrm{cm}^{-1}\right)$ : 3410, 1660, 1615 in good agreement with [42].

${ }^{1} \mathrm{H} \mathrm{NMR}\left(\mathrm{CDCl}_{3}, 600 \mathrm{MHz}\right) \delta_{\mathrm{H}}: 0.77(3 \mathrm{H}, \mathrm{s}, 18-\mathrm{H}), 3.63(1 \mathrm{H}, \mathrm{t}, J=8.5 \mathrm{~Hz}, 17 \alpha-\mathrm{H}), 3.90(1 \mathrm{H}, \mathrm{d}$, $\left.J=11 \mathrm{~Hz}, 19-\mathrm{CH}_{2}-\right), 4.06\left(1 \mathrm{H}, \mathrm{dd}, J_{1}=1 \mathrm{~Hz}, J_{2}=11 \mathrm{~Hz}, 19-\mathrm{CH}_{2}-\right), 5.94(1 \mathrm{H}$, br s, $4-\mathrm{H}) ;{ }^{13} \mathrm{C} \mathrm{NMR}\left(\mathrm{CDCl}_{3}\right.$, $151 \mathrm{MHz}) \delta_{\mathrm{C}}: 11.1$ (C-18), 21.2 (C-11), 23.2 (C-15), 30.4 (C-16), 31.7 (C-7), 33.4 (C-6), 33.5 (C-2), 35.0 (C-8), 36.3 (C-12), 36.7 (C-1), 42.9 (C-13), 43.9 (C-10), 50.8 (C-14), 54.0 (C-9), 66.0 (C-19), 81.5 (C-17), 127.0 (C-4), 166.6 (C-5), 199.9 (C-3). The NMR spectra of 12 are attached as Supplementary Figures S1 and S2.

19-Nortestololactone (13) (127 mg, 85\% mol): $\mathrm{C}_{18} \mathrm{H}_{24} \mathrm{O}_{3}$, Found: C, 74.90; H, 8.36. Requires C, 74.97; H, 8.39; mp. $195-198{ }^{\circ} \mathrm{C}$ (lit. $196-199{ }^{\circ} \mathrm{C}$ [23]), IR: $v_{\max }\left(\mathrm{cm}^{-1}\right): 1725,1670,1610$.

${ }^{1} \mathrm{H}$ NMR $\left(\mathrm{CDCl}_{3}, 600 \mathrm{MHz}\right) \delta_{\mathrm{H}}: 1.36(3 \mathrm{H}, \mathrm{s}, 18-\mathrm{H}), 5.84(1 \mathrm{H}, \mathrm{s}, 4-\mathrm{H}) ;{ }^{13} \mathrm{C} \mathrm{NMR}\left(\mathrm{CDCl}_{3}, 151 \mathrm{MHz}\right)$ : 19.8 (C-18), 20.0 (C-15), 26.3 (C-1), 27.0 (C-11), 28.5 (C-16), 29.7 (C-7), 35.0 (C-6), 36.4 (C-2), 38.9 (C-8), 42.3 (C-10), 42.6 (C-12), 45.03 (C-14), 48.2 (C-9), 82.9 (C-13), 124.8 (C-4), 164.7 (C-5), 171.2 (C-17), 199.5 (C-3). The spectroscopic data are in agreement with those reported in the literature [24]. The NMR spectra of $\mathbf{1 3}$ are attached as Supplementary Figures S3 and S4.

\section{Conclusions}

Biotransformations of nine steroidal substrates in the cultures of the filamentous fungus Penicillium vinaceum AM110 have been carried out. The series of androstene substrates underwent mostly Baeyer-Villiger oxidation (lactonization), without side processes; the metabolic fate of these substrates is therefore less complicated than in the other species of Penicillium genus, while the transformation kinetics and achieved yields are very promising. Interesting inhibition of the BVMO activity was observed when a hydroxyl function was inserted at the C-19 methyl group. Instead of any oxidation process, the C-17 carbonyl group of 19-hydroxyandrostenedione was reduced to the hydroxyl group.

The fate of androstane steroids, epiandrosterone and androsterone, was more complicated. Two possible sites of oxidation, the C-3 hydroxyl and the C-17 carbonyl groups, were oxidized correspondingly to the ketone and to the $\delta$-lactone with different rates. This allows for the potential design of the biotransformation process to obtain preferentially only one of the oxidation products. The transformation of epiandrosterone in comparison with its unsaturated analogue (DHEA) and androsterone was much slower and occurred with much lower efficiency.

The presented results suggest usefulness of the Penicillium vinaceum AM110 strain in the commercial preparation of biologically active $\delta$-lactones of androstene and androstane series via microbial Baeyer-Villiger oxidation. 
Supplementary Materials: The following is available online, a PDF file containing Figures S1-S6: ${ }^{1} \mathrm{H}$ and ${ }^{13} \mathrm{C}$ NMR spectra of products 12 and 13, GC spectra of products 12 and 13 obtained during time course experiments.

Author Contributions: Conceptualization, A.P. and A.Ś.; methodology, A.P. and A.Ś.; investigation, A.P., P.Ł., and A.Ś.; writing-original draft preparation, A.P. and A.Ś.; writing-review and editing, A.P. and A.Ś.; project administration, A.P. All authors have read and agreed to the published version of the manuscript.

Funding: This research received no external funding.

Acknowledgments: We acknowledge the help of MSc Student Kamila Gogola during part of the biotransformation experiment.

Conflicts of Interest: The authors declare no conflict of interest.

\section{References}

1. Malard, L.A.; Pearce, D.A. Microbial diversity and biogeography in Arctic soils. Environ. Microbiol. Rep. 2018, 10, 611-625. [CrossRef]

2. Duarte, A.W.F.; dos Santos, J.A.; Vianna, M.V.; Vieira, J.M.F.; Mallagutti, V.H.; Inforsato, F.J.; Wentzel, L.C.P.; Lario, L.D.; Rodrigues, A.; Pagnocca, F.C.; et al. Cold-adapted enzymes produced by fungi from terrestrial and marine Antarctic environments. Crit. Rev. Biotechnol. 2018, 38, 600-619. [CrossRef]

3. Oroz-Guinea, I.; Sanchez-Moreno, I.; Mena, M.; Garcia-Junceda, E. Hyperthermophilic aldolases as biocatalyst for C-C bond formation: Rhamnulose 1-phosphate aldolase from Thermotoga maritima. Appl. Microbiol. Biotechnol. 2015, 99, 3057-3068. [CrossRef]

4. Birolli, W.G.; Lima, R.N.; Porto, A.L.M. Applications of Marine-Derived Microorganisms and Their Enzymes in Biocatalysis and Biotransformation, the Underexplored Potentials. Front. Microbiol. 2019, 10, 1453. [CrossRef] [PubMed]

5. Gilman, J.C.; Abbott, E.V. A summary of the soil fungi. Iowa State Coll. J. Sci. 1927, 1, 225-343.

6. Nicoletti, R.; Trincone, A. Bioactive Compounds Produced by Strains of Penicillium and Talaromyces of Marine Origin. Mar. Drugs 2016, 14, 37. [CrossRef] [PubMed]

7. Asiri, I.A.; Badr, J.M.; Youssef, D.T. Penicillivinacine, antimigratory diketopiperazine alkaloid from themarine-derived fungus Penicillium vinaceum. Phytochem. Lett. 2015, 13, 53-58. [CrossRef]

8. Romagnolo, A.; Spina, F.; Risso, S.; Brenna, E.; Crotti, M.; Varese, G.C. A competitive approach for the reduction of unsaturated compounds based on fungal ene-reductases. Mycosphere 2016, 7, 1588-1599. [CrossRef]

9. Casali, M.; Tarantini, L.; Riva, S.; Hunkova, Z.; Weignerova, L.; Kren, V. Exploitation of a library of $\alpha$-galactosidases for the synthesis of building blocks for glycopolymers. Biotechnol. Bioeng. 2002, 77, 105-110. [CrossRef]

10. Worldwide Patent Application no. WO2005054491A1. Available online: https://patents.google.com/patent/ WO2005054491A1/en (accessed on 7 July 2020).

11. US Patent no. US5344994. Available online: https://patents.google.com/patent/US5344994A/en (accessed on 7 July 2020).

12. Republic of Poland Patent no. PL 226320B1. Available online: https://patents.google.com/patent/PL226320B1/ en (accessed on 7 July 2020).

13. Baeyer, A.; Villiger, V. Einwirkung des Caro'schen Reagens auf Ketone. Ber. Dtsch. Chem. Ges. 1899, 32, 3625-3633. [CrossRef]

14. Krow, G.R. The Baeyer-Villiger Oxidation of Ketones and Aldehydes. Org. React. 1993, 43, $251-798$. [CrossRef]

15. ten Brink, G.-J.; Arends, I.W.C.E.; Sheldon, R.A. The Baeyer-Villiger Reaction: New Developments toward Greener Procedures. Chem. Rev. 2004, 104, 4105-4123. [CrossRef] [PubMed]

16. Ilovaisky, A.I.; Merkulova, V.M.; Vil', V.A.; Chernoburova, E.I.; Shchetinina, M.A.; Loguzov, S.D.; Dmitrenok, A.S.; Zavarzin, I.V.; Terent'ev, A.O. Regioselective Baeyer-Villiger Oxidation of Steroidal Ketones to Lactones Using $\mathrm{BF}_{3} / \mathrm{H}_{2} \mathrm{O}_{2}$. Eur. J. Org. Chem. 2020, 402-405. [CrossRef]

17. De Gonzalo, G.; Mihovilovic, M.D.; Fraaije, M.W. Recent Developments in the Application of Baeyer-Villiger Monooxygenases as Biocatalysts. ChemBioChem 2010, 11, 2208-2231. [CrossRef] [PubMed]

18. Leisch, H.; Morley, K.; Lau, P.C.K. Baeyer-Villiger Monooxygenases: More Than Just Green Chemistry. Chem. Rev. 2011, 111, 4165-4222. [CrossRef] 
19. Turfitt, G.E. The microbiological degradation of steroids: 4. Fission of the steroid molecule. Biochem. J. 1948, 42, 376-383. [CrossRef]

20. Fried, J.; Thoma, R.W.; Klingsberg, A. Oxidation of Steroids by Micro-Örganisms. III. Side Chain Degradation, Ring D-Cleavage and Dehydrogenation in Ring A. J. Am. Chem. Soc. 1953, 75, 5764-5765. [CrossRef]

21. Abaffy, T.; Bain, J.R.; Muehlbauer, M.J.; Spasojevic, I.; Lodha, S.; Bruguera, E.; O’Neal, S.K.; Kim, S.Y.; Matsunami, H. A Testosterone Metabolite 19-Hydroxyandrostenedione Induces Neuroendocrine Trans-Differentiation of Prostate Cancer Cells via an Ectopic Olfactory Receptor. Front. Oncol. 2018, 8, 162. [CrossRef]

22. Wang, J.; Zhang, Y.; Liu, H.; Shang, Y.; Zhou, L.; Wei, P.; Yin, W.-B.; Deng, Z.; Qu, X.; Zhou, Q. A biocatalytic hydroxylation-enabled unified approach to C19-hydroxylated steroids. Nat. Commun. 2019, 10, 3378. [CrossRef]

23. McCurdy, J.T.; Garrett, R.D. Microbiological transformation of steroids. I. Synthesis of 19-nortestololactone. J. Org. Chem. 1968, 33, 660-661. [CrossRef]

24. Bartmańska, A.; Dmochowska-Gładysz, J.; Huszcza, E. Steroids' transformations in Penicillium notatum culture. Steroids 2005, 70, 193-198. [CrossRef] [PubMed]

25. Franceschini, S.; van Beek, H.L.; Pennetta, A.; Martinoli, C.; Fraaije, M.W.; Mattevi, A. Exploring the Structural Basis of Substrate Preferences in Baeyer-Villiger Monooxygenases: Insight from Steroid Monooxygenase. J. Biol. Chem. 2012, 287, 22626-22634. [CrossRef] [PubMed]

26. Fürst, M.J.L.J.; Savino, S.; Dudek, H.M.; Gómez Castellanos, J.R.; Gutiérrez de Souza, C.; Rovida, S.; Fraaije, M.W.; Mattevi, A. Polycyclic Ketone Monooxygenase from the Thermophilic Fungus Thermothelomyces thermophila: A Structurally Distinct Biocatalyst for Bulky Substrates. J. Am. Chem. Soc. 2017, 139, 627-630. [CrossRef]

27. Panek, A.; Świzdor, A.; Milecka-Tronina, N.; Panek, J.J. Insight into the orientational versatility of steroid substrates-a docking and molecular dynamics study of a steroid receptor and steroid monooxygenase. J. Mol. Model. 2017, 23, 96. [CrossRef]

28. Brannon, R.; Parrish, F.W.; Wiley, B.J.; Long, L., Jr. Microbial transformation of a series of androgens with Aspergillus tamarii. J. Org. Chem. 1967, 32, 1521-1527. [CrossRef]

29. Hunter, A.C.; Carragher, N.E. Flexibility of the endogenous progesterone lactonisation pathway in Aspergillus tamarii KITA: Transformation of a series of cortical steroid analogues. J. Steroid Biochem. Mol. Biol. 2003, 87, 301-308. [CrossRef]

30. Hunter, A.C.; Coyle, E.; Morse, F.; Dedi, C.; Dodd, H.T.; Koussoroplis, S.J. Transformation of 5-ene steroids by the fungus Aspergillus tamarii KITA: Mixed molecular fate in lactonization and hydroxylation pathways with identification of a putative $3 \beta$-hydroxy-steroid dehydrogenase $/ \Delta^{5}-\Delta^{4}$ isomerase pathway. Biochim. Biophys. Acta 2009, 1791, 110-117. [CrossRef]

31. Kołek, T.; Szpineter, A.; Świzdor, A. Baeyer-Villiger oxidation of DHEA, pregnenolone, and androstenedione by Penicillium lilacinum AM111. Steroids 2008, 73, 1441-1445. [CrossRef]

32. Kołek, T.; Szpineter, A.; Świzdor, A. Studies on Baeyer-Villiger oxidation of steroids: DHEA and pregnenolone D-lactonization pathways in Penicillium camemberti AM83. Steroids 2009, 74, 859-862. [CrossRef]

33. Mascotti, M.L.; Palazzolo, M.A.; Bisogno, F.R.; Kurina-Sanz, M. Biotransformation of dehydro-epiandrosterone by Aspergillus parasiticus: Metabolic evidences of BVMO activity. Steroids 2016, 109, 44-49. [CrossRef]

34. Świzdor, A.; Panek, A.; Milecka-Tronina, N. Microbial Baeyer-Villiger oxidation of $5 \alpha$-steroids using Beauveria bassiana. A stereochemical requirement for the $11 \alpha$-hydroxylation and the lactonization pathway. Steroids 2014, 82, 44-52. [CrossRef] [PubMed]

35. Świzdor, A. Baeyer-Villiger Oxidation of Some $\mathrm{C}_{19}$ Steroids by Penicillium lanosocoeruleum. Molecules 2013, 18, 13812-13822. [CrossRef] [PubMed]

36. Świzdor, A.; Panek, A.; Ostrowska, P. Metabolic fate of pregnene-based steroids in the lactonization pathway of multifunctional strain Penicillium lanosocoeruleum. Microb. Cell. Fact. 2018, 17, 100. [CrossRef] [PubMed]

37. Lobastova, T.G.; Khomutov, S.M.; Donova, M.V. Formation of hydroxylated steroid lactones from dehydroepiandrosterone by Spicaria fumoso-rosea F-881. Appl. Biochem. Microbiol. 2015, 51, 180-187. [CrossRef]

38. Yildirim, K.; Uzuner, A.; Gulcuoglu, E.Y. Biotransformation of some steroids by Aspergillus terreus MRC 200365. Collect. Czech. Chem. Commun. 2010, 75, 665-673. [CrossRef] 
39. Yang, B.; Wang, Y.; Chen, X.; Feng, J.; Wu, Q.; Zhu, D.; Ma, Y. Biotransformations of steroids to testololactone by a multifunctional strain Penicillium simplicissimum WY134-2. Tetrahedron 2014, 70, 41-46. [CrossRef]

40. Kozłowska, E.; Urbaniak, M.; Hoc, N.; Grzeszczuk, J.; Dymarska, M.; Stępień, Ł.; Pląskowska, E.; Kostrzewa-Susłow, E.; Janeczko, T. Cascade biotransformation of dehydroepiandrosterone (DHEA) by Beauveria species. Sci. Rep. 2018, 8, 13449. [CrossRef]

41. Kozłowska, E.; Matera, A.; Sycz, J.; Kancelista, A.; Kostrzewa-Susłow, E.; Janeczko, T. New 6,19-oxidoandrostan derivatives obtained by biotransformation in environmental filamentous fungi cultures. Microb. Cell Fact. 2020, 19, 37. [CrossRef]

42. Ehrenstein, M.; Otto, K. Investigations on Steroids. XXX. New Transformation Products of Strophanthidin: 19-Hydroxytestosterone, 19-Hydroxy-1-dehydrotestosterone Diacetate and Estradiol-17ß. J. Org. Chem. 1959, 24, 2006-2012. [CrossRef]

43. Sebek, O.K.; Reineke, L.M.; Peterson, D.H. Intermediates in the metabolism of steroids by Penicillium lilacinum. J. Bacteriol. 1962, 83, 1327-1331. [CrossRef]

Sample Availability: Samples of the compounds 12 (17 $\beta, 19$-dihydroxyandrost-4-en-3-one) and 13 (19-nortestololactone) are available from the authors.

(C) 2020 by the authors. Licensee MDPI, Basel, Switzerland. This article is an open access article distributed under the terms and conditions of the Creative Commons Attribution (CC BY) license (http://creativecommons.org/licenses/by/4.0/). 